\title{
PERCEPTION OF LEARNING IN PROGRAMMING LECTURES BASED ON MENTAL MODELS
}

\author{
Elias J. R. Freitas ${ }^{1 *}$, Luiz O. Carvalho ${ }^{1}$ and Venilson L. B. Fonseca ${ }^{2}$ \\ ${ }^{1}$ Federal Institute of Minas Gerais - Campus Avançado Itabirito \\ ${ }^{2}$ Federal Institute of Minas Gerais - Campus Ouro Preto
}

\begin{tabular}{l}
\hline ARTICLE INFO \\
\hline Article History: \\
Received $15^{\text {th }}$ July, 2020 \\
Received in revised form \\
$11^{\text {th }}$ August, 2020 \\
Accepted $26^{\text {th }}$ September, 2020 \\
Published online $30^{\text {th }}$ October, 2020 \\
\hline
\end{tabular}

Key Words:

Metal model; Programming;

Learning; Education.

*Corresponding author: Elias J. R. Freitas,

\begin{abstract}
The understanding of the human mind and its ability to learn are objects of research in Cognitive Science. The way a person learns is unique, the result of her previous experiences and the development of her mental model. The understanding of how the students produce their mental models can favor the learning of several disciplines, as evidenced in several papers. In this context, this work investigates the combination of mental models used by students within the lecture of Programming in technical education classes. The analysis was based on a test that identifies strengths and weaknesses in the structuring of mental models.
\end{abstract}

Copyright (C) 2020, Elias J. R. Freitas et al. This is an open access article distributed under the Creative Commons Attribution License, which permits unrestricted use, distribution, and reproduction in any medium, provided the original work is properly cited.

Citation: Elias J. R. Freitas, Luiz O. Carvalho and Venilson L. B. Fonseca. 2020. "Perception of learning in programming lectures based on mental models", International Journal of Development Research, 10, (10), 41375-41377.

\section{INTRODUCTION}

Cognitive Science is an interdisciplinary scientific study of the human mind in a structured way from different perspectives (Bermúdez, 2020; Teixeira, 1998). Each person internally creates a set of rules, thoughts, and ways of interacting with reality from facts, experiences, and intuition referred to as a "mental model" (Craik, 1943). Mental models can be seen as software that the brain has programmed, based on the combination and reorganization of cognitive building blocks to perform each activity. Naturally, each person is unique and reacts to a given stimulus in a different way, which leads to a variety of mental models possibilities. In order to investigate mental models, the work in Moreira et al. (2008) proposed the use of semi-structured interviews supported by conceptual maps. Other studies such as those described in Vosniadou (1994) and Duque, Paula, Santos \& Vieira Jr. (2015) proposed to apply a questionnaire of generic questions of the evaluated content. From the gathered responses, it is possible to verify the existence of the main concepts, the clarity of the hierarchy presented, the proper use of connections, and the crossing of information. In addition, the authors suggested numerical indexes to obtain a score, determining which mental model the interviewee is closest to concerning one of the predetermined models. The knowledge about mental models is important from an educational perspective, as evidenced by the work in Johnson-Laird (1983). That author understands the learning as the building of mental models of what is being taught, and the act of teaching as a way to facilitate the construction and review of those mental models. Therefore, knowing the way the students develop and combine multiple mental models enables the teacher to facilitate the student learning, once the teacher can use systematized strategies that allow the construction and recombination of these cognitive structures (Moreira \& Pinto, 2003; Pinto 2019). In this context, the present study investigates the combination of mental models used by students to solve computational problems, within the Programming lectures in technical education classes. This investigation is indirect since it does not aim at determining the various mental models that students may have, but to obtain groups of mental models instead. In this way, it is possible to check the mastery and learning of the students. Thus, this paper also intended to highlight weaknesses and strengths of the students, and challenges to overcome in learning programming, assisting the teacher in the search for 
methodological tools and actions that enable the development or review the mental models of the students.

\section{METHODOLOGY AND METHODS}

The resolution of a computational problem involves a minimum range of concepts, as depicted in the conceptual map in Figure 1. These concepts form a branched structure of the necessary bases and must be assimilated by the students. In the present study, the resolution of computational problems refers to problems whose solution can be achieved in an algorithmic way, that is, through a sequence of steps. Those are welldefined problems and their solutions are based on logic and mathematics, familiar to high school / technical students. Therefore, the first assumption is that a set of questions related to the resolution of computational problems can indicate the presence of a set of mental models developed by the students.

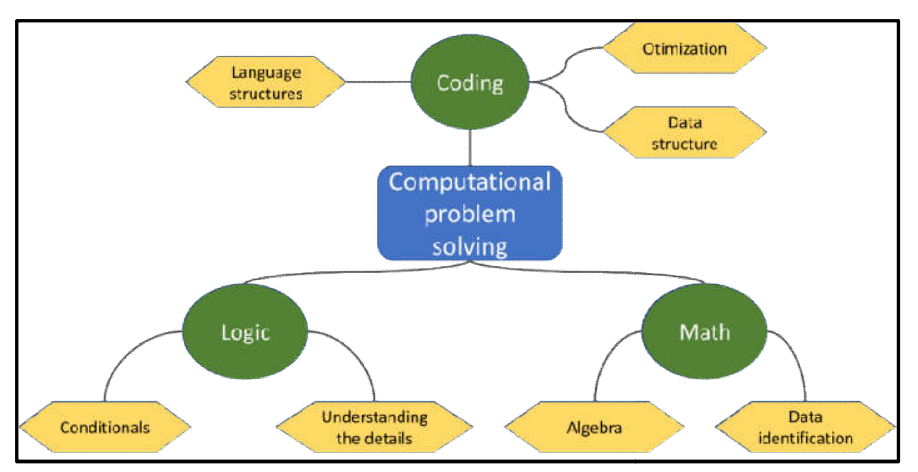

Figure 1. Conceptual map for solving computational problems

In addition, the second assumption is that the set of mental models built by the students can be grouped into conceptual levels to determine the domain of the related concepts. Once a student when solving a computational problem often uses more than one mental model, it is feasible to identify conceptual levels and use them to realize the building and the flaws in the learning process of the students. Similar to the studies of Borges (1999) and Duque et al. (2015), which proposed conceptual levels to measure the evolution of mental models in order of complexity, the present study also proposes a sequence of conceptual levels and their definitions for solving computational problems:

- Level 0 (the absence of mental model): deficit in notions of logic and / or basic mathematics, showing no ability to solve basic daily issues and to solve computational problems.

- Level 1 (mechanistic): ability to solve logic and basic mathematics problems, identifying, from given examples, the solution of the questions related to daily life, but which is unable to abstract to the computational level.

- Level 2 (algebraic): ability to solve logic and mathematics problems, identifying the solution of questions related to daily life and indicating some ability to abstract to the computational level. However, the student does not pay attention to important details of logic, which makes the correct abstraction for coding hard.

- Level 3 (algorithmic): ability to solve basic logic and mathematics problems, identifying the solution of questions related to daily life and indicating good abilities to abstract to the computational level. Although the student pays attention in details of logic, he/she fails to carry out a more in-depth analysis of more complex problems.

- Level 4 (scientific): ability to analyze and implement more elaborate computational problems, mastering both logic and mathematics and devising a solution in a sequence of instructions, also for more complex and comprehensive problems.

Based on those assumptions, we elaborated an evaluation questionnaire with 9 questions, which 5 questions have the quiz format, and the remaining 4 questions are discursive. The proposed questions aims at covering all concepts depicted in Figure 1, focusing on logic and mathematics applied in a practical way, the ability to analyze pseudocodes and the synthesis of those concepts in the coding stage. The evaluation questionnaire is based on familiar subjects to the students and the questions were disposed in a random way so that they do not provide a logic reasoning sequence. Aiming at identifying the conceptual levels associated to a set of mental models the evaluation questionnaire is measured in the range 0 to 100 points. According to the obtained score in the evaluation, each student is then classified as belonging to a particular conceptual level.

\section{RESULTS AND DISCUSSION}

The evaluation questionnaire was applied to 59 students enrolled in the Technical Course in Industrial Automation integrated to the High School of the Federal Institute of Minas Gerais - Campus Itabirito. That course is composed of three grades (1st, 2nd and 3rd), where the 2 nd and 3rd grades were evaluated. From the amount of participating students, $18 \%$ related to have interest for the programming area. The first experiment analyzed the obtained scores for each grade. The results are depicted in Figure 2 and Figure 3. In both figures, the $\mathrm{x}$-axes contain the identification numbers of each student (randomly distributed), whereas the y-axes indicate the obtained scores in the evaluation questionnaire. In addition, each plot presents three curves. The first curve indicates the score, the second and the third curves denote, respectively, the minimum and the maximum expected score for that grade, according to the lecture and subjects previously studied along the first grade of the course.

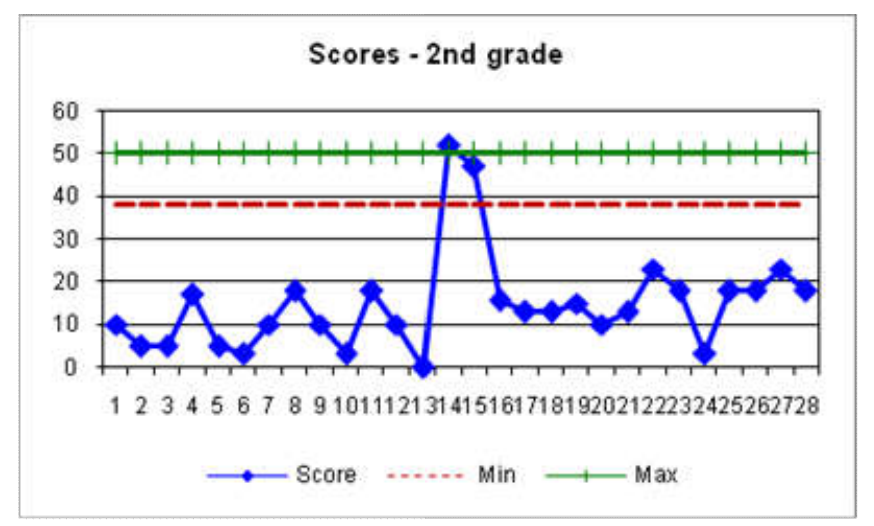

Figure 2. Obtained scores for 2nd grade

The plot in Figure 2 shows that only 2 students of the 2nd grade achieved the expected score: between 38 and 50 points. Whereas just one student obtained a score over the expected, the remaining ones were ranked below the minimum expected score. 


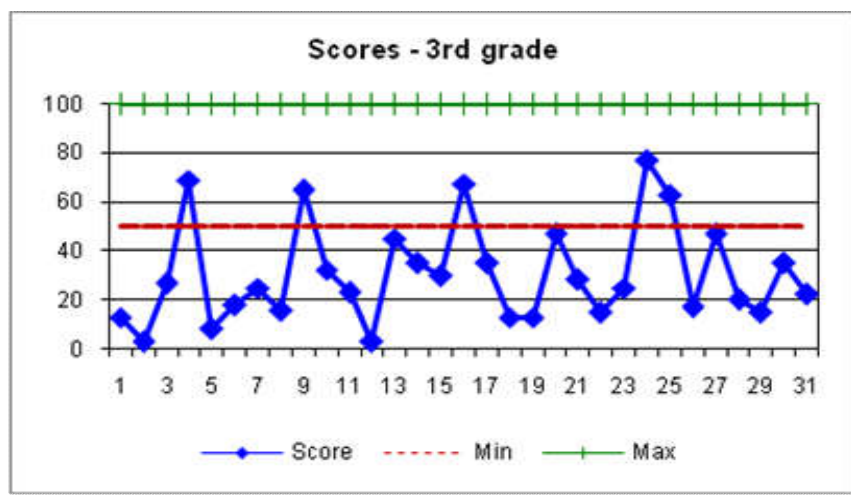

Figure 3. Obtained scores for 3rd grade

In a similar way, Figure 3 presents the same analysis of the obtained scores, but now with respected to the 3rd grade class. At a first sight, the 3rd grade students were already presented to all concepts involved in the evaluation questionnaire. Therefore, they are able to achieve the conceptual levels 3 and 4 , and achieve a score lying in the range 50 to 100 . In Figure 3 , the plot shows that only 5 students achieved scores in the expected range, whereas the remaining students were below the minimum delineated value.

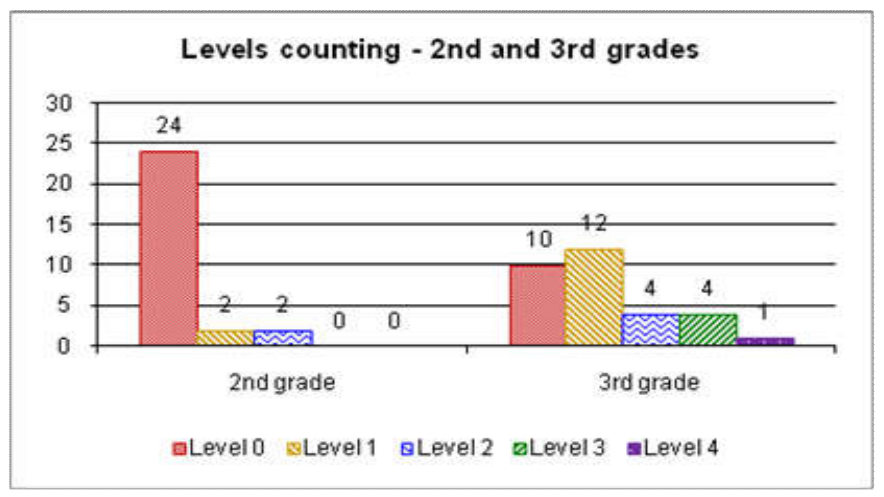

Figure 4. Histogram of conceptual levels for 2 nd and 3 rd grades

Figure 4 presents the histogram of the conceptual levels obtained by the 2 nd and 3rd grades. In Figure 4, it is possible to observe that there was no student in the 2 nd grade achieving the conceptual levels 3 and 4. In fact, according to the established range of scores for the 2 nd grade, such a result was expected. For the 2 nd grade class, $86 \%$ students are in the conceptual level $0,7 \%$ students are in the level 1 , and $7 \%$ students are in the level 2. Figure 4 also presents the histogram of conceptual levels of the 3rd grade. In Figure 4, it is possible to observe that $39 \%$ 3rd grade students are in the conceptual level $0,43 \%$ students are in the level 1 , the same amount of $14 \%$ students are in levels 2 and 3 , and $4 \%$ students are in the conceptual level 4. From the results depicted in Figure 4, we infer that the continuity of lectures such as Mathematics and Programming along the 2nd grade of the technical course contributes to the evolution of the mental models developed by the students. Although the obtained results are in general below the initially conceived, it was observed that whereas in the 2 nd grade there was no student in level 2, the 3 rd grade presented 29\% students classified in levels 2, 3 and 4 .

\section{Conclusions}

This work presented an investigation of the perception of learning in the programming lectures of technical education, based on mental models.
A set of conceptual levels was proposed to identify the level of maturity of the mental models developed by the students, considering three key points: the ability to think logically, the mathematical background required to perform calculations, and the adjustment to the structures of the programming language. From those three key points, an evaluation questionnaire was proposed as a method to group mental models and to identify the conceptual levels. Analyzing the answers provided to the evaluation questionnaire, the investigated classes presented levels below than the expected, even after coursing the lectures that provide the knowledge for solving the proposed problems. However, as also observed in the results, from the 2 nd grade class to the 3rd grade class, it was possible to notice improvements in the development of the mental models built by the students. In that context, such evolution of mental models is explained by the continuity of Mathematics and Programming courses in the education process. Once the students keep studying the referred lectures, those topics tend to become familiar to student perception, so that an evolution is observed. Furthermore, many mistakes made by students refer to previous teaching stages, mainly in text interpretation/comprehension and in the mathematical formulation. Thus, aiming at the occurring of an effective learning, the previous stages of education must be improved in order to enable the students to develop their mental models.

\section{REFERENCES}

BERMÚDEZ, J. (2020) Cognitive science: an introduction to the science of the mind, Cambridge University Press, Cambridge, United Kingdom.

BORGES, A. T. (2010) Como evoluem os modelos mentais, Ensaio Pesquisa em Educação em Ciências. 1, pp. 66-92.

CRAIK, K. J. W. (1943) The nature of exploration, Cambridge University Press, Cambridge, United Kingdom.

DUQUE, T. O., PAULA, F. S., SANTOS, H. M. and VIEIRA JR., N. (2015) Falhas nas avaliações tradicionais em diversos níveis de escolaridade: um estudo envolvendo tópicos de matemática financeira através de níveis e subníveis de modelos mentais, Revista Brasileira de Pesquisa em Educação em Ciências. 15, pp. 427-452.

JOHNSON-LAIRD, P. (1983) Mental models, Harvard University Press, Cambridge, USA.

MOREIRA, M. A. and PINTO, A. O. (2003) Dificuldades dos alunos na aprendizagem da Lei de Ampère à luz da teoria dos modelos mentais de Johnson-Laird, Revista Brasileira de Ensino de Física. 25, pp. 317-325.

MOREIRA, M. A., SOARES, S. and PAULO, I. C. (2008) Mapas conceituais como instrumento de avaliação em um curso introdutório de mecânica quântica, Revista Brasileira de Ensino de Ciência e Tecnologia. 1, pp. 1-12.

PINTO, C. M. (2019) A escola ensina os seres humanos a pensar, mas somos todos ciborgues, Ciências \& Cognição. 24, pp. 265-275.

TEIXEIRA, J. F. (1998) Mentes e máquinas: uma introdução à ciência cognitiva. Artmed, Porto Alegre, Brazil.

VOSNIADOU, S. (1994) Capturing and modeling the process of conceptual change, Learning and Instruction. 4, pp. 4569 . 